\title{
Retraction: the cellular source for APOBEC3G's incorporation into HIV-1
}

Jing Ma ${ }^{1,4,3+}$, Xiaoyu $\mathrm{Li}^{1 \dagger}$, Jian $\mathrm{Xu}^{1 \dagger}$, Quan Zhang ${ }^{1}$, Zhenlong Liu', Pingping Jia', Jinming Zhou', Fei Guo ${ }^{2}$, Xuefu You', Liyan Yu', Lixun Zhao ${ }^{1}$, Jiandong Jiang ${ }^{1}$ and Shan Cen ${ }^{1,3,4^{*}}$

The authors would like to retract the article "The cellular source for APOBEC3G's incorporation into HIV1 "[1]. After publication of the article, the authors realized that the electrophoretic images in Figure 4D/E, showing a reproducible result of their previous publication [2] (cited as reference 6 [1]), was mistakenly taken from the same images used in [2]. In addition, Figure $2 \mathrm{~B}$ is an unintended duplicate image of Figure 1B. This should have been avoided by the authors' careful proofreading of the manuscript. The authors apologize to the readers, reviewers, and editors of Retrovirology for publishing these erroneous data.

\begin{abstract}
Author details
'Institute of Medicinal Biotechnology, Chinese Academy of Medical Science, Beijing, PR China. ${ }^{2}$ State Key Laboratory for Molecular Virology and Genetic Engineering, Institute of Pathogen Biology, Chinese Academy of Medical Science, Beijing, PR China. ${ }^{3}$ Lady Davis Institute for Medical Research and McGill AIDS Centre, Jewish General Hospital, Montreal, Quebec, Canada.

${ }^{4}$ Microbiology \& Immunology, McGill University, Montreal, Quebec, Canada.
\end{abstract}

Received: 27 October 2011 Accepted: 5 November 2011

Published: 5 November 2011

\section{References}

1. Ma Jing, Li Xiaoyu, Xu Jian, Zhang Quan, Liu Zhenlong, Jia Pingping,

Zhou Jinming, Guo Fei, You Xuefu, Yu Liyan, Zhao Lixun, Jiang Jiandong, Cen Shan: The cellular source for APOBEC3G's incorporation into HIV-1. Retrovirology 2011, 8:2.

2. Cen S, Guo F, Niu M, Saadatmand J, Deflassieux J, Kleiman L: The interaction between HIV-1 Gag and APOBEC3G. J Biol Chem 2004, 279:33177-33184.

\footnotetext{
* Correspondence: shan.cen@mcgill.ca

† Contributed equally

'Institute of Medicinal Biotechnology, Chinese Academy of Medical Science, Beijing, PR China

Full list of author information is available at the end of the article
}

Submit your next manuscript to BioMed Central and take full advantage of:

- Convenient online submission

- Thorough peer review

- No space constraints or color figure charges

- Immediate publication on acceptance

- Inclusion in PubMed, CAS, Scopus and Google Scholar

- Research which is freely available for redistribution

Submit your manuscript at www.biomedcentral.com/submit

\section{() Biomed Central}

\section{Biomed Central}

